\section{Quality Assurance for Distance Learning in a Global Society}

\section{Ronald A. Phipps}

Ronald A. Phipps is senior associate of the Institute for Higher Education Policy. Address: Institute for Higher Education Policy, 1320 19th Street NW, Washington D.C. 20036.

$\mathrm{C}$ yberspace, the electronic marketplace, Internet, World Wide Web, the information highway, e-mail, the digital highway, virtual learning, information technology - all of these terms are used to describe, explain, or illustrate a phenomenon that is inexorably transforming the worldwide higher education enterprise. Don Tapscott declares: "Today we are witnessing the early, turbulent days of a revolution as significant as any other in human history. A new medium of human communications is emerging, one that may prove to surpass all previous revolutions - the printing press, the telephone, the television, the computer-in its impact on our economic and social life." Carol Twigg, James Mingle, and Robert Hetrick of Educom predict that by the end of the decade, there will be one billion users of the Internet-considerably more than the conservative estimate of about 50 million today. Moreover, higher education will no longer take place within the silos of individual institutions (or even their virtual equivalents). Instead, higher education will occur within a dynamic global marketplace of customers and suppliers.

Technology-mediated distance learning comes in a variety of forms and defies the creation of a clear taxonomy or clear definition of providers. Trying to grasp this remarkable phenomenon is akin to holding on to quicksilver. Technology is constantly being upgraded, software is being developed, and alliances are being formed-all at an astounding rate. The landscape of technology-mediated learning is an ever-changing mosaic.

Although technology-mediated distance learning is offered by thousands of individual traditional institutions, a growing number of consortia and brokering arrangements among traditional institutions, hundreds of corporate universities, and the military branches, some of the first institutions established solely and specifically to provide technology-mediated distance learning were established outside of the United States in countries such as China, France, India, Indonesia, Iran, Korea, Spain, and South Africa. One of the first institutions of this kind is Open University in Great Britain, which was established in 1969. Since then, 30 other open universities have been established throughout the world. The number of students served is impressive. For in- stance, in 1995, the China TV University System enrolled 530,000 students, the Anadolu University in Turkey enrolled 577,804 students, and the Universitas Terbuka in Indonesia taught 353,000 students. These institutions are major higher education providers in their countries.

There appear to be four interrelated phenomena accompanying the rapid growth of information technology's impact upon the global postsecondary education community. These cultural and technological catalysts are pervasive and transcend the various characteristics of providers of postsecondary education. They are: the emergence of lifelong learning, efforts to make instruction more learnercentered, the desire to provide access irrespective of where a student lives, and the development of "knowledge media."

\section{Lifelong Learning}

The world has changed in ways that make lifelong learning more of a necessity than an appealing phrase. In their book, The Monster Under the Bed, Davis and Botkin note that in an agrarian economy, education for young people between 7 and 14 was sufficient to last 40 years of a working life. The industrial economy expanded the age range of students to between 5 and 22. In the information economy, the rapid pace of technological change requires education to be updated throughout our working lives. People have to increase their learning power to sustain their earning power. Lifelong learning is the norm that is augmenting school-age education.

\section{Technology-mediated distance learning comes in a variety of forms and defies the creation of a clear taxonomy or clear definition of providers.}

\section{Learner-centered Instruction}

Mingle points out that, traditionally, higher education is organized around the needs of the providers, where a "place" to conduct research and teach is supplied. The standards for conducting research and teaching, including faculty workload, space for labs, etc. are centered on the provider and professional needs. These concerns, however, are not the concerns of a "learner-centered" environment. The concept of learning productivity, coined by Bruce Johnstone, former chancellor of the State University of New York, is at the heart of the shift from "teacher-centered" to "learner-centered" delivery systems-and it possesses three fundamental character- 
istics. It is, to a greater degree, self-directed; it is more focused and purposeful; and it employs the appropriate level of faculty mediation. In talking to his colleagues regarding the role of the faculty in a learner-centered environment, Robert Swain asserts the following:

The real roles of the professor in an information-rich world will not be to provide information, but to guide students wading through the deep waters of the information flood. Professors in this environment will thrive as mentors. They will use the best skills they have now to nudge students through the educationally crucial task of processing information, problem solving, analysis, and synthesis of ideas-the activities in which our time can be best spent.

\section{The real roles of the professor in an information-rich world will not be to provide information, but to guide stu- dents wading through the deep wa- ters of the information flood.}

\section{Providing Access}

For several years, it has been recognized that learning does not only have to take place on a college or university campus. In 1994, the U.S. government announced its intention to establish by the year 2000 the National Information Infrastructure (NII), which is essentially a broad-band digital network. One fundamental requirement is that the applications of the NII extend into homes and workplaces as well as colleges and universities. A plethora of courses and entire academic programs are already being provided to students in venues away from the campus, particularly in a student's home or workplace.

\section{Knowledge Media}

The term "knowledge media" was proposed by Marc Eisenstadt to describe the convergence of telecommunications, computing, and the learning or cognitive sciences. "Knowledge media are about the capturing, storing, imparting, sharing, accessing and creating of knowledge." The combination of technologies coupled with our understanding of the learning process will fundamentally change the relationship between people and knowledge. This medium is not just a technical format, such as a CD-ROM or e-mail, but encompasses the entire presentational style, how the user interfaces, the accessibility of the medium, and the degree of interactivity. Knowledge media provide the opportunity to change the emphasis from the classroom and teach- ing to the individual and learning. In short, with good learning materials, effective networks, and proper support, students can learn better at home than in class.

\section{What is Quality?}

There is not universal agreement within the international higher education community regarding the definition of quality. Debate continues about the relative merits of input variables, process variables, and outputs as they relate to student learning and institutional effectiveness. Nevertheless, it is tempting, and in many ways convenient, to use the instructional processes and activities of "traditional" higher education as the benchmark upon which technology-mediated distance learning is judged. In effect, by comparing technology-mediated learning to the traditional ways in which students are taught in colleges and universities, there is an implicit assumption that traditional higher education is the paragon of quality and any deviation from that model represents "less" quality. To be sure, there is something to be said about the rich culture of higher education. On the other hand, using the status quo as a framework for evaluation of quality of technology-mediated distance learning leaves little room for realizing the enormous potential and impact of information technology.

This is not to suggest that the pedagogy used for centuries be abandoned. The teaching-learning process of higher education has long been a combination of faceto-face meetings-ranging from tutorials to large lectures-asynchronous communications (such as written assignments), and guided independent work (like reading and laboratory assignments). Through the application of information technology, however, a wide variety of options are now available and, although these fundamental pedagogies are still part of the teaching-learning process, they are reconfigured and enhanced.

\section{The world has changed in ways that make lifelong learning more of a ne- cessity than an appealing phrase.}

Moreover, there is no disagreement that colleges and universities are in the "knowledge" business. Yet, the traditional focus on the acquisition of knowledgeembodied in the degree to which institutions possess human, information, physical, and financial resourcesis being challenged. Because of information technology and the extraordinary wealth of information that is now 
commonly available, it is appropriate to address the extent to which institutions are able to access knowledge and use it in the teaching-learning process. Indeed, what information technology does best is deliver content and provide access to information and to other people.

Thus, while recognizing that higher education enterprises create knowledge and disseminate knowledge through a variety of pedagogies, it is suggested that the policies and practices of traditional higher education need not be used as the sole point of departure for an understanding of quality. Instead, although informed by the fruitful heritage of traditional higher education, the following practices are offered as appropriate quality assurance strategies to be considered when learning takes place at a distance. Each of these strategies focuses particularly on the needs of the learner, enjoys support from a number of practitioners of distance learning, and is found in a growing body of literature.

\section{Teaching Methods}

Interactivity. A substantial body of evidence suggests that the more interactive the instruction, the more effective the learning outcome is likely to be. The key ingredients appear to be the availability of the instructorwhether through direct person-to-person contact or through electronic means-and the intellectual engagement of the student, regardless of the method of engagement.

Modular Learning. Considerable evidence exists that individualized instructional approaches emphasizing small, modularized units of content, mastery of one unit before moving to the next, immediate and frequent feedback to students on their progress, and active student involvement in the learning process are consistently effective in enhancing subject matter learning over more traditional learning formats such as lecture and recitation.

Collaboration. Learning is enhanced through cooperation and reciprocity among students. The learning process involves collaboration and a social context, with students working together. Sharing ideas in a group setting improves thinking and deepens understanding. Study groups, collaborative learning, group problem solving, and discussion of assignments can be dramatically strengthened through technology-mediated learning.

Learning Styles. Students learn in many different ways and bring to the learning activity varied talents and experiences. Technology has the enormous potential to enable students to learn in a variety of ways. Technology-mediated distance learning can provide dramatic visuals and well-organized print; encourage self-reflection and self-evaluation; and promote collaboration and group problem solving.

\section{Faculty Involvement}

Contacts between Faculty and Students. Chickering observes that faculty contact in and out of class is very important in student motivation and involvement. The concern of faculty often helps students get through rough times and continue their studies. Computer conferencing, e-mail, and the World Wide Web increase opportunities for students and faculty to converse and exchange work much more speedily than before and more thoughtfully and "safely" than when confronting each other in classroom or faculty office.

Courseware Development. Courseware is, by and large, produced either by individual faculty (or groups of faculty members) on campuses or in commercial enterprises-or a combination of both. Regardless of the source of courseware development, the knowledge, skills, and competency levels should be clearly defined and determined or approved by faculty possessing the appropriate academic and professional experience. Also, with respect to courseware developed commercially, the institutions should validate the academic quality of the materials and ensure that the courseware is consistent with the goals and objectives of the institution's curriculum.

\section{Knowledge media are replacing the professor as the student's primary source of information.}

Information Access. Knowledge media are replacing the professor as the student's primary source of information. Since faculty are no longer the major source of information, of particular importance is the ability of faculty to guide students through the morass of the Internet to identify the reliability of information. In addition, faculty should be capable of identifying or creating courseware that evokes student motivation, and encourages interactivity, collaboration, and modular learning activities.

Faculty Selection and Training. Not every faculty member will have the skills and temperament for technology-mediated learning. In addition to careful selection of faculty members, proper training with respect to 
learner needs and the use of technology is essential. Training needs to be continuous because of the changing requirements of technology.

\section{Support Services}

An integrated team-such as computer service technicians, counselors, site administrators, distribution clerks, and library resource personnel-is needed to support faculty efforts.

Learning Resources. Libraries and learning resources are being transformed by technology. The rapid pace of replacing traditional libraries and resource centers with computer networks and on-line retrieval systems requires that students and faculty, staff, and administrators be provided ongoing orientation and training sessions for accessing information.

Student Services. There is a growing movement for colleges and universities to contract for student services, including registration, business office, financial aid, and bookstore functions. Institutions that use outside sources must be diligent in ensuring that students receive clear, complete, and timely information regarding institutional requirements, assumptions about technological competence and skills, technical equipment requirements, and availability of support services and that students have easy access to services. Of particular importance is technical assistance for students so that the technology becomes a "transparent" conduit of knowledge.

Infrastructure. Ensuring that students participating in learning activities do not experience interruptions or problems in communications, the institution's technological infrastructure needs to be continually monitored and, if appropriate, enhanced. Major components include expanded network capacity, addition of dial-in ports for remote access, enhancement of e-mail, fileserving and other centralized services, creation of a software library, and enhancement of network security.

\section{Assessment of Learning}

Outcomes Assessment. Almost two decades ago, Howard Bowen observed that in higher education true outcomes in the form of learning and personal development of students are on the whole unexamined and only vaguely discerned. It is becoming increasingly important (and some would say imperative) for institutions participating in technology-mediated distance learning to identify a clearly understood set of outcomes, and especially student knowledge, skills, and competency levels. Once these student learning outcomes are identified, reliable and valid methods for measuring their achievement should be developed. As the concept of "seat-time" be- comes less and less relevant, especially as a proxy for student learning, externally validated outcomes-preferably determined through multiple measures-provide the institution and its constituents evidence that learning has taken place.

These quality assurance strategies represent many of the best practices used by experienced providers of distance learning combined with teaching-learning methods that have withstood the test of time in colleges and universities around the world.

\section{References}

Howard Bowen, The Cost of Higher Education (San Francisco: Jossey-Bass, 1980).

Arthur W. Chickering and Stephen C. Ehremann, "Implementing the Seven Principles," AAHE Bulletin, October, 1996.

Commission on Higher Education, Middle States Association of Colleges and Schools, Guidelines for Distance Education Programs (Philadelphia: CHE, March, 1997).

Sir John S. Daniel, Mega-Universities and Knowledge Media: Technology Strategies for Higher Education (London: Kogan Page Limited, 1996).

Sir John S. Daniel, "Why Universities Need Technology Strategies," Change, July/August, 1997.

Stan Davis and Jim Botkin, The Monster Under the Bed (New York: Simon \& Shuster, 1995).

Kenneth C. Green and Steven W. Gilbert, "Great Expectations: Content, Communications, Productivity, and the Role of Information Technology,” Change, March/April, 1995.

Robert C. Hetrick, Jr., James R. Mingle, and Carol A. Twigg, The Public Policy Implications of a Global Learning Infrastructure (Washington, D.C. Educom, 1997), 4-5.

James R. Mingle, "Vision and Reality for Technology-Based Delivery Systems in Postsecondary Education" (paper presented at the Governor's Conference on Higher Education, St. Louis, 1995).

Ernest Pascarella and Patrick Terenzini, How College Affects Students (San Francisco: Jossey-Bass, 1991).

David Sumler and Barbara Zirkin, "Interactive or Non-Interactive? That is the Question," Fournal of Distance Education, (spring 1995).

Robert Swain, "Our Roles as Faculty Must Change or We'll Go the Way of the Railroads," Linkages 6, no. 1 (fall 1997).

Don Tapscot, The Digital Economy: Promise and Peril in the Age of Networked Intelligence (New York: McGraw-Hill, 1996).

\section{Internet Resource}

For more information on issues related to international and comparative higher education, visit the Center's website, located at:

http://www.bc.edu/bc_org/avp/soe/cihe/ 